It is found that both probes gave an intense signal for air bubbles but that only probe $\mathrm{D}$ gave particle signals, although the latter were weak in the dispersed zone. This fact is more clearly seen in Fig. 4 (b) for a dense bubbling zone. Since the highest voltage of the $\mathrm{A} / \mathrm{D}$ converter was set at $2.5 \mathrm{~V}$, the higher part of the signal for the bubble phase, which reached about $4 \mathrm{~V}$, was cut. However, one may readily distinguish the characteristic signals for bubbles from those for particles.

Figure 5 shows an example of the enlarged figure for the beginning of the bubble phase and its end, for checking the response time of probe D. It took only about $200 \mu \mathrm{s}$ for the signal to rise from the level of the liquid phase to that of the bubble phase, shown in (a), and vice versa, shown in (b). This response time is found to be short enough to measure the size and velocity of bubbles in a three-phase fluidized bed.
By these experiments it is shown that the optical fiber, although brittle, has enough mechanical strength to resist the violent movement of solid particles, showing the wide applicability of the proposed probe to gas-liquid-solid particle systems.

\section{Literature Cited}

1) Abuaf, N., O. C. Jones, Jr. and G. A. Zimmer: Rev. Sci. Instrum., 49, 1090 (1978).

2) Hirama, T., M. Ishida and T. Shirai: Kagaku Kogaku Ronbunshu, 1, 272 (1975).

3) Ishida, M., A. Nishiwaki and T. Shirai: "Fluidization", ed. by J. R. Grace and J. M. Matsen, p. 357, Plenum Press (1980).

4) Ishida, M. and H. Tanaka: Preprint for the research meeting on three-phase fluidized beds held in Atsugi by The Soc. of Chem. Engrs., Japan, Dec. 1981.

5) Oki, K., T. Akehata, and T. Shirai: Kagaku Kōgaku, 37, 965 (1973).

\title{
GAS HOLDUP ON A PERFORATED PLATE
}

\author{
Toshiro MiYAHARA, Yorishige MATSUBA, SAtoru KASENO and TERUo TAKAHASHI \\ Department of Industrial Chemistry, Okayama University, Okayama 700
}

Gas holdup in a bubble column having perforated plates has been studied by many investigators ${ }^{1-3}$ and a considerable number of relevant papers have been published. However, there remain uncertainties in the correlation equations. The gas holdup in a bubble column in which a gas is usually dispersed through a deep pool of liquid is not influenced by liquid depth. The authors ${ }^{5}$ have reported previously that gas holdup in shallow liquid is correlated well with the Froude number based on liquid depth. However, we have found no reports which describe gas holdup with consideration of liquid depth, although knowledge about the effect of liquid depth on gas holdup is very important for the design and operation of such gas-liquid contacting devices.

In the present report, we describe an extension of our studies ${ }^{5}$ of gas holdup on a perforated plate in relation to liquid depth using a variety of plate geometries, plate materials, column diameters, liquid depths and physical properties of liquids. Some interesting data are also reported on the gas holdup on a perforated plate.

Received February 4, 1982. Correspondence concerning this article should be addressed to T. Miyahara. Y. Matsuba is now at Harima Chemicals, Inc., Kakogawa City 675.

\section{Experimental Apparatus and Procedure}

Details of experimental apparatus are found in a previous paper $^{4)}$, with column diameters of 0.05 and $0.1 \mathrm{~m}$ and a column height of $1.3 \mathrm{~m}$. Dimensions and materials of plates are shown in Table 1. We used water and ethanol as liquids, the same as were used in the work already described ${ }^{4}$.

Gas holdup was calculated by the usual static pressure method. Most tests were carried out with liquid depths of 0.3 to $1 \mathrm{~m}$. Previous experimental values $^{5}$ obtained by the authors in shallow liquid of 0.03 to $0.5 \mathrm{~m}$ in depth are also used.

\section{Results and Discussion}

The vertical profile of gas holdup obtained by the static pressure method presents a constant value up to around the top of the froth for low superficial gas velocity in the present experiments. Therefore, we take the constant value as the gas holdup on a plate in a liquid with depth of 0.3 to $1 \mathrm{~m}$.

The authors ${ }^{5}$ have shown previously that gas holdup in shallow liquid is correlated to the Froude number $\operatorname{Fr}\left(=U_{g c}{ }^{2} /(g H)\right)$. Then the gas-to-liquid hold- 


\begin{tabular}{|c|c|c|c|c|c|c|c|c|}
\hline Plate & $d_{o}[\mathrm{~m}]$ & $m[-]$ & $P_{d}[\mathrm{~m}]$ & $l[\mathrm{~m}]$ & $P_{d} / d_{o}[-]$ & $D_{T}[\mathrm{~m}]$ & Material & $(1-\Psi)_{\max } *[-]$ \\
\hline$P-1$ & 0.0005 & 19 & 0.01 & 0.001 & 20 & 0.05 & Brass & 0.264 \\
\hline $\mathrm{P}-2$ & 0.001 & 19 & 0.01 & 0.001 & 10 & 0.05 & Brass & 0.216 \\
\hline$P-3$ & 0.0005 & 37 & 0.007 & 0.001 & 14 & 0.05 & Brass & 0.287 \\
\hline $\mathrm{P}-4$ & 0.0005 & 85 & 0.01 & 0.001 & 20 & 0.1 & Brass & 0.272 \\
\hline$P-5$ & 0.0013 & 84 & 0.01 & 0.0008 & 7.69 & 0.1 & Brass & 0.206 \\
\hline P- 6 & 0.0018 & 84 & 0.01 & 0.0008 & 5.56 & 0.1 & Brass & 0.187 \\
\hline$P-7$ & 0.0015 & 19 & 0.01 & 0.001 & 6.67 & 0.05 & Teflon & 0.192 \\
\hline P- 8 & 0.0005 & 19 & 0.01 & 0.002 & 20 & 0.05 & Polyethylene & 0.264 \\
\hline P- 9 & 0.0005 & 19 & 0.01 & 0.002 & 20 & 0.05 & Polyvinyl chloride & 0.264 \\
\hline $\mathrm{P}-10$ & 0.001 & 19 & 0.01 & 0.002 & 10 & 0.05 & Polyvinyl chloride & 0.216 \\
\hline $\mathrm{P}-11$ & 0.0015 & 19 & 0.01 & 0.002 & 6.67 & 0.05 & Polyvinyl chloride & 0.192 \\
\hline $\mathrm{P}-12$ & 0.0005 & 19 & 0.01 & 0.002 & 20 & 0.05 & Acrylic resin & 0.264 \\
\hline $\mathrm{P}-13$ & 0.0005 & 19 & 0.01 & 0.001 & 20 & 0.05 & Telfion & 0.264 \\
\hline$P-14$ & 0.0008 & 19 & 0.01 & 0.001 & 12.5 & 0.05 & Teflon & 0.23 \\
\hline $\mathrm{P}-15$ & 0.001 & 19 & 0.01 & 0.001 & 10 & 0.05 & Tefion & 0.216 \\
\hline
\end{tabular}

* calculated from Eq. (6)

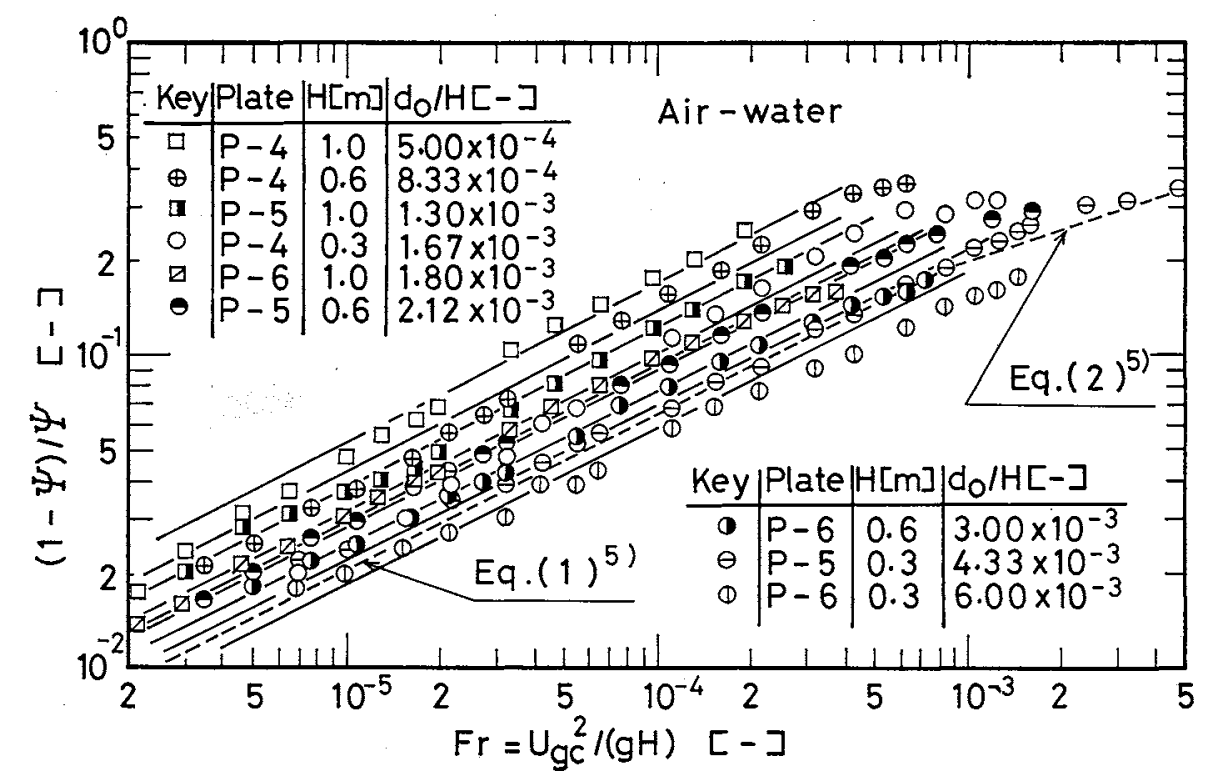

Fig. 1 Gas-liquid holdup ratio vs. Froude number

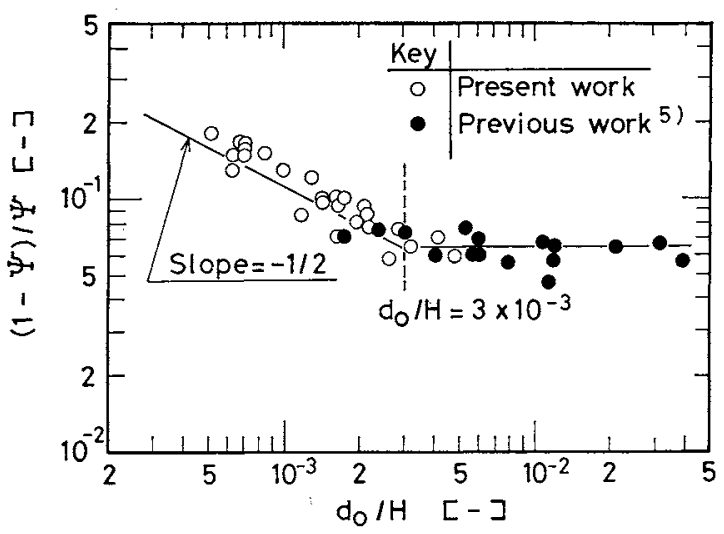

Fig. 2 Effect of $d_{o} / H$

up ratio in a deep liquid of $0.3 \mathrm{~m}$ to $1 \mathrm{~m}$ depth in this study is presented in Fig. 1 in terms with $(1-\Psi) / \Psi$ against $F r$. The dashed lines, given by the following equations,

$$
\begin{array}{ll}
(1-\Psi) / \Psi=6.5 \sqrt{F r} & F r<8.5 \times 10^{-4} \\
(1-\Psi) / \Psi=2 \sqrt[3]{F r} & 8.5 \times 10^{-4}<F r<1
\end{array}
$$

are the results by the authors ${ }^{5}$ in a shallow liquid of 0.03 to $0.5 \mathrm{~m}$ depth. The Froude number range of this study is mostly $\mathrm{Fr}<8.5 \times 10^{-4}$. From this chart, $(1-\Psi) / \Psi$ values are in satisfactory agreement with Eq. (1) for large $d_{o} / H$, whereas for small $d_{0} / H$ they are larger than those of Eq. (1). However, $(1-\Psi) / \Psi$ values increase proportionally to $\mathrm{Fr}^{1 / 2}$. Further, for large Froude number, it seems that $d_{o} / H$ does not affect gas holdup and experimental values approach the results calculated by Eq. (2).

Figure 2, which includes the previous empirical results $^{5)}$ by the authors, shows the relation between $(1-\Psi) / \Psi$ and $d_{o} / H$ at $F r=10^{-4}$. When $d_{o} / H$ is less than about $3 \times 10^{-3}$, gas holdup is independent of liquid depth and becomes a function of hole diameter for the slope of $-1 / 2$, as shown in Fig. 2. 


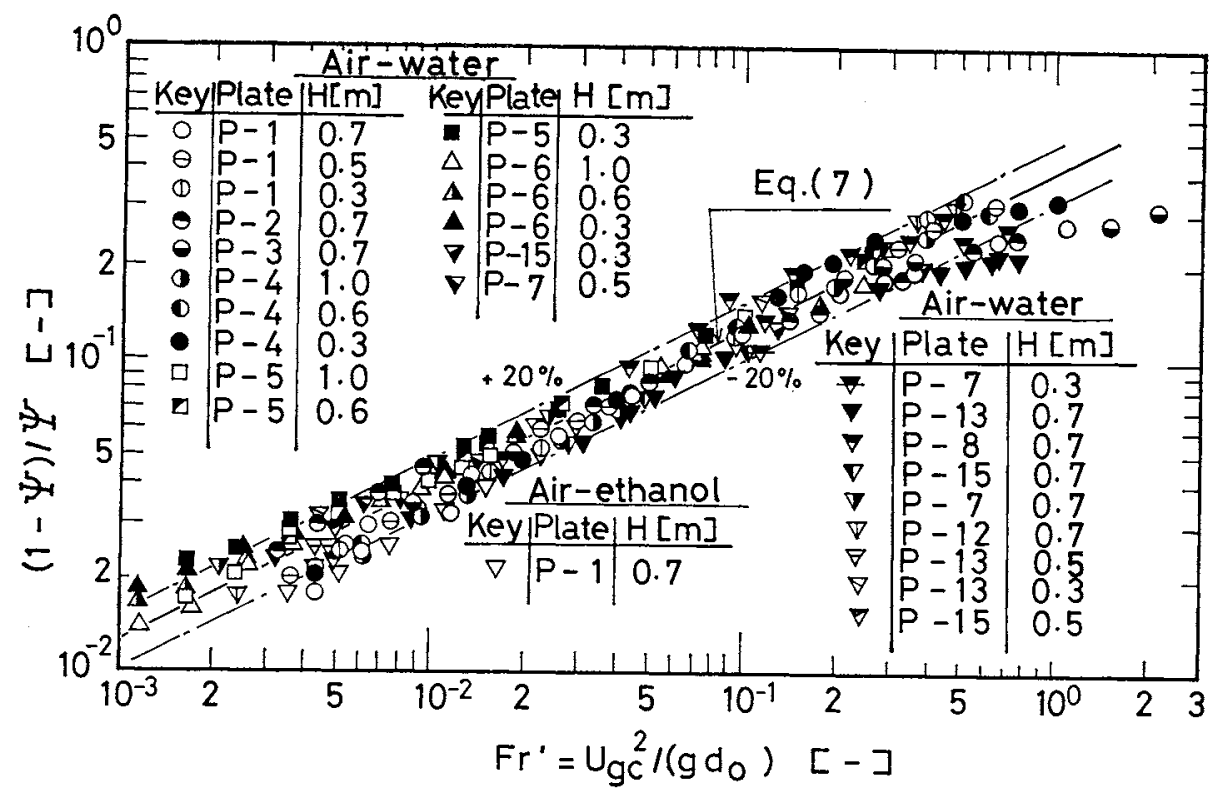

Fig. 3 Correlation of $(1-\Psi) / \Psi$

From these results, Eq. (1) can be rewritten in the form

$$
(1-\Psi) / \Psi=\text { const. }\left(d_{o} / H\right)^{n}\left(U_{g c} / \sqrt{g \bar{H}}\right)
$$

Putting $n=-1 / 2$ for $d_{0} / H<3 \times 10^{-3}$ or $n=0$ for $d_{o} / H>3 \times 10^{-3}$, we obtain

$$
\begin{aligned}
(1-\Psi) / \Psi & =\text { const. }\left(d_{o} / H\right)^{-1 / 2}\left(U_{g c} / \sqrt{g H}\right) \\
& =\text { const. }\left(U_{g c} / \sqrt{\left.g d_{o}\right)}\right. \\
& =\text { const. } \sqrt{F r^{\prime}} \quad d_{o} / H<3 \times 10^{-3} \\
\left(1-\Psi^{\prime}\right) / \Psi & =\text { const. }\left(d_{o} / H\right)^{\circ}\left(U_{g c} / \sqrt{g H}\right) \\
& =\text { const. }\left(U_{g o} / \sqrt{g H)}\right. \\
& =\text { const. } \sqrt{F r} \quad d_{o} / H>3 \times 10^{-3}
\end{aligned}
$$

Therefore, we have made Fig. 3 in terms of $(1-\Psi) / \Psi$ vs. $F_{r}{ }^{\prime}\left(=U_{g c}{ }^{2} /\left(g d_{o}\right)\right)$.

In a bubble column, it is well known that a transition from bubble to turbulent circulation flow occurs by increasing gas velocity, and the maximum gas holdup is observed in the vicinity where the transition occurs. We have also observed the phenomenon in this work.

The maximum gas holdup is given for the air-water system by the following equation ${ }^{6}$.

$$
(1-\Psi)_{\max }=0.0083\left\{m P_{d} /\left(d_{o} D_{T}^{2}\right)\right\}^{0.29}
$$

In Fig. 3, experimental values which are smaller than those calculated by Eq. (6) are correlated. Maximum values from Eq. (6) are listed in Table 1. $(1-\Psi) / \Psi$ becomes a function of $\mathrm{Fr}^{\prime}$ independently of liquid depth, plate material, column diameter and physical properties of liquids in the range of the present experiments.

From these experimental results, the following

* Experimental conditions were as follows ${ }^{6}$ :

$P_{d}=\sim 0.06 \mathrm{~m}, d_{o}=0.002-0.0035 \mathrm{~m}$

$D_{T}=0.102 \mathrm{~m}, L_{T}=2 \mathrm{~m}, U_{g c}=\sim 0.3 \mathrm{~m} / \mathrm{s}$ empirical equation is obtained.

$$
\begin{aligned}
& (1-\Psi) / \Psi=0.4 \sqrt{F r^{\prime}} \quad d_{o} / H<3 \times 10^{-3} \\
& (1-\Psi)<(1-\Psi)_{\max }
\end{aligned}
$$

It seems that $(1-\Psi) / \Psi$ in $d_{o} / H>3 \times 10^{-3}$ or turbulent circulation flow regime could be estimated by Eqs. (1) and (2) as described above.

$$
\begin{aligned}
& \text { Nomenclature } \\
& \begin{array}{lll}
D_{T} & =\text { column diameter }
\end{array} \\
& \begin{array}{lll}
d_{0} & =\text { hole diameter }
\end{array} \\
& \text { Fr } \quad=\begin{array}{l}
\text { Froude number based on liquid depth } \\
\left(=U_{g e}{ }^{2} /(g H)\right)
\end{array} \\
& \begin{aligned}
\mathrm{Fr}^{\prime} \quad= & \text { Froude number based on hole diameter } \\
& \left(=U_{g c}{ }^{2} /\left(g d_{o}\right)\right)
\end{aligned} \\
& g \quad=\text { gravitational acceleration } \quad\left[\mathrm{m} / \mathrm{s}^{2}\right] \\
& H \quad=\text { liquid depth [m] } \\
& \begin{array}{lll}
L_{T} & =\text { column height }
\end{array} \\
& l \quad=\text { plate thickness [m] } \\
& m \quad=\text { number of holes [-] } \\
& P_{d} \quad=\text { pitch } \quad[\mathrm{m}] \\
& U_{g e} \quad=\text { superficial gas velocity } \quad[\mathrm{m} / \mathrm{s}] \\
& \begin{array}{lll}
\Psi & =\text { liquid holdup } & {[-]} \\
(1-\Psi)_{\max } & =\text { maximum gas holdup }
\end{array}
\end{aligned}
$$

\section{Literature Cited}

1) Akita, K. and F. Yoshida: Ind. Eng. Chem., Process Des. Dev., 12, 76 (1973).

2) Hughmark, G. A.: ibid., 6, 218 (1967).

3) Mashelkar, R. A.: Brit. Chem. Eng., 15, 1297 (1970).

4) Miyahara, T., Y. Matsuba and T. Takahashi: Kagaku Kogaku Ronbunshu, 8, 13 (1982).

5) Takahashi, T., T. Miyahara and K. Shimizu: J. Chem. Eng. Japan, 7, 75 (1974).

6) Yamashita, F. and H. Inoue: ibid., 8, 334 (1975). 